\title{
Detection of Flooding and Drying inside a PEM Fuel Cell Stack
}

\author{
Andrej Debenjak1,, - Matej Gašperin ${ }^{1,2}$ - Boštjan Pregelj1,3 - Maja Atanasijević-Kunc 4 - \\ Janko Petrovčič 1,3 - Vladimir Jovan 1,3 \\ 1 Jožef Stefan Institute, Slovenia \\ ${ }^{2}$ University of West Bohemia, Faculty of Electrical Engineering/RICE, Plzeň, Czech Republic \\ ${ }^{3}$ Centre of Excellence for Low-carbon technologies - CO NOT, Slovenia \\ ${ }^{4}$ University of Ljubljana, Faculty of Electrical Engineering, Slovenia
}

\begin{abstract}
Proton Exchange Membrane (PEM) fuel cells are currently seen as the most suitable choice for implementation into daily-use applications. However, the PEM technology does not yet fulfil all the necessary requirements that the mass-market demands and proper strides towards elimination of remaining issues have to be taken. Hence, in this paper, the focus is made on water management faults, i.e. flooding and drying. More precisely, it deals with detection of them with the use of Electrochemical Impedance Spectroscopy (EIS). The EIS was successfully applied as a diagnostic tool to a fuel cell stack consisted of 80 cells without usage of any special purpose measurement equipment, where, in addition to the stack current, only voltage of the complete stack was measured. The paper describes the modifications that were made on the EIS to make it capable of handling the diagnostics of fuel cell stacks. The results of the experimental study show that the approach is successful in detecting the flooding and drying faults and that for detection only excitation signals with frequencies between $30 \mathrm{and} 300 \mathrm{~Hz}$ are required. Based on the experimental data and conclusions, a diagnostic decision algorithm is proposed.
\end{abstract}

Keywords: PEM fuel cell system, electrochemical impedance spectroscopy, diagnostics, flooding, drying

\section{O INTRODUCTION}

Hydrogen fuel cells with Proton Exchange Membrane (PEM) [1] and [2] present a potential alternative to existing internal combustion engines [3]. PEM fuel cells are energy conversion devices that convert chemical energy of hydrogen fuel, which can be produced in different ways [4] and [5], directly into electricity with high efficiency [6]. In addition to the electricity as the main product, they also produce heat, water and no greenhouse gases. Further, PEM fuel cells operate at low operating temperatures, use oxygen from the air, have high specific power $(\mathrm{kW} / \mathrm{kg})$, and have short start-up and shut-down times. All this makes them suitable for various kinds of stationary and transportation applications. However, the successful introduction of the PEM fuel cell technology to everyday applications depends on the durability and reliability of this technology on one hand, and a reduction in the costs of production, operation, and maintenance on the other [7] and [8].

Research is done on various issues that affect PEM fuel cells performance [9] and [10]. One wide research field deals with material degradation, where the main role plays corrosion of the electrodes and degradation of the membranes [11] and [12]. Next, catalyst and membrane poisoning is an irreversible process influencing fuel cell life-time [13] and [14]. Another aspect is connected to temperature. It was shown that higher temperatures negatively affect the characteristics of the membranes [15]. On the other hand, the PEM fuel cells are also sensitive to sub-zero temperatures [16].

Recent studies have shown that the durability and reliability of a PEM fuel cell system is vitally affected by water management faults [9] and [17]. A precise balance of liquid and vapour water inside each cell needs to be maintained to ensure the optimal performance of the stack. An inadequate water balance leads to two different conditions, which both have a direct effect on the performance of the stack. First, an insufficient removal of the produced water leads to flooding of the gas channels, and secondly, an excessive water removal or too dry inlet gases cause membrane drying. Furthermore, in case of severe and long-term drying, irreversible damage to the membrane may occur. In order to improve the reliability and durability the two faults have to be detected, classified, and finally, proper control action has to be taken to eliminate the faults and prevent the system from faulty operation and possible damage.

Fuel cell flooding and membrane drying are faults that cannot be measured directly, therefore proper diagnostics method has to be applied. Electrochemical impedance spectroscopy (EIS) [18] is an effective method for diagnosing fuel cell flooding and drying [19] and [20]. In [21], the authors suggested parameter identification of proposed fuel cell model through the use of impedance measurements. The approach gains good identification results, but the identification works only with single cells. A stack similar to the one used in our study was tested in [22]. The authors used laboratory measuring equipment and reported they 
can detect drying, flooding and anode poisoning. Still, the used equipment is prohibitively expensive for industrial usage and in contrast to our work, voltage of all the cells in the stack have to be measured. Multi-sine test signals were also successfully applied to the fuel cells in order to perform the EIS [23]. The approach is useful, since it shortens the time needed for the measurements. However, the benefit comes with a price, i.e. more demanding computation and excitation equipment. This is why we used single-sine signals in spite of the multi-sine's benefits.

Two main advantages of the EIS method are its ability to distinguish between fuel cell flooding and drying, and non-invasive in-situ measurements. The EIS has been already proved as a successful tool for detecting flooding and drying in laboratory environment where only single fuel cells were tested, whereas stack level diagnostics has not been given much attention yet. In a recent work, the method was used on a laboratory stack consisting of 20 cells without using any dedicated EIS equipment [24]. However, the total equipment costs were still almost $€ 20,000$, which makes any proposed implementation unfeasible for commercial systems.

This paper presents an attempt towards the use of the EIS as an on-line diagnostic tool on larger fuel cell systems without relying on special purpose measurement equipment, where only total stack impedance is measured. The purpose is to detect and classify the flooding and drying faults of commercial systems consisting of a few dozens of fuel cells. The main issue with such an approach is that the faults may occur only in a few cells, whereas only total impedance of the stack is measured, which makes the faults hard to detect. There were three main objectives within the study. The first was to build up a low cost measurement system in such a way that on the one hand, it will be sensitive enough to perform the EIS measurements, and will be costs-acceptable for implementation in commercial systems on the other. The second was to adapt the method's computation procedure to be effective in real-life measurements. And the third was to test and validate the method on a real-life system.

\section{EXPERIMENTAL METHOD}

Electrochemical reactions involve many processes and parameters. In the PEM fuel cells, some of them are influenced by the hydration of membranes and presence of liquid water formed inside the cells. These influences can be detected by using EIS, which enables an insight into electrochemical reactions [18].
EIS basically measures the frequency response (impedance characteristic) of an electrochemical process and analyses it. The theoretical procedure for acquiring impedance at a specific frequency consists of three steps, namely exciting the process, measuring both excitation and response signals, and performing computation of the impedance. The process must be excited by a perturbation signal that consists of DC and $\mathrm{AC}$ (sinusoidal) components. The DC component determines the operational point of the process, and the AC component represents the perturbation signal. In case of the measurement in galvanostatic mode (i.e. applying current excitation signal) and assuming the system is linear near an operating point, the current excitation signal and the process' voltage response can be presented as functions of time:

$$
\begin{gathered}
i(t)=I_{d c}+I_{0} \sin \left(\omega_{0} t\right), \\
u(t)=U_{d c}+U_{0} \sin \left(\omega_{0} t+\varphi\right),
\end{gathered}
$$

where $t$ denotes time, $\omega_{0}$ the angular frequency, $I_{d c}$ and $U_{d c}$ the signal's DC component, $I_{0}$ and $U_{0}$ the signal's AC amplitudes, and $\varphi$ the phase shift of the voltage response signal.

For further computation the $\mathrm{AC}$ components of both signals are expressed as phasors at an angular frequency $\omega_{0}$. In this case, both signals can be written as:

$$
\begin{gathered}
I=I_{0} e^{j \omega_{0} t}, \\
U=U_{0} e^{j\left(\omega_{0} t+\varphi\right)} .
\end{gathered}
$$

Finally, the impedance at an angular frequency $\omega_{0}$ can be calculated using Ohm's law:

$$
Z=\frac{U}{I}=\frac{U_{0} e^{j\left(\omega_{0} t+\varphi\right)}}{I_{0} e^{j \omega_{0} t}}=Z_{0} e^{j \Phi},
$$

where $Z_{0}$ is the impedance gain, and $\Phi$ is the impedance phase angle. By measuring the impedances at different frequencies of interest, the impedance characteristic is obtained and can further be used for analysis.

\section{EXPERIMENTAL}

\subsection{Measurement Setup}

The measurement setup is schematically presented in Fig. 1. It consists of three main subgroups of equipment. The first is a fuel cell system, the second represents a load, and the third consists of sensors and data acquisition (DAQ) equipment. 
The experiments were performed on a commercial PEM fuel cell based power unit presented in Fig. 2. With a stack of 80 PEM fuel cells, the unit produces up to $8.5 \mathrm{~kW}$ of electric power. The unit's detailed specifications are collected in Table 1. In addition to the stack, the unit consists of all the required subsystems for autonomous operation (including a hydrogen recirculation pump, an air delivery system with blower, a cooling system, and electronics). The important feature of the unit is that it does not include a humidifier for inlet gases. Since the aim is to measure the impedance characteristics of the unit in presence of flooding and drying inside the stack, this feature allows flooding and drying to be provoked by setting extreme conditions.

Table 1. PEM fuel cell system specifications

\begin{tabular}{ll}
\hline Parameter & Value \\
\hline Surface Area & $200 \mathrm{~cm}^{2}$ \\
\hline No. of Cells & 80 \\
\hline Max Power & $8.5 \mathrm{~kW}$ \\
\hline Voltage Range & 40 to $80 \mathrm{~V}$ \\
\hline Max Current & $190 \mathrm{~A}$ \\
\hline Peak Net Efficiency & $50 \%$ \\
\hline
\end{tabular}

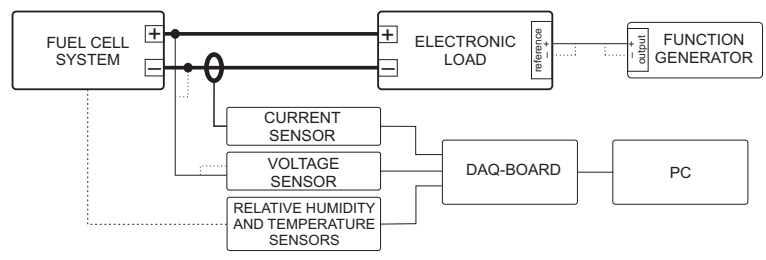

Fig. 1. Measurement setup scheme

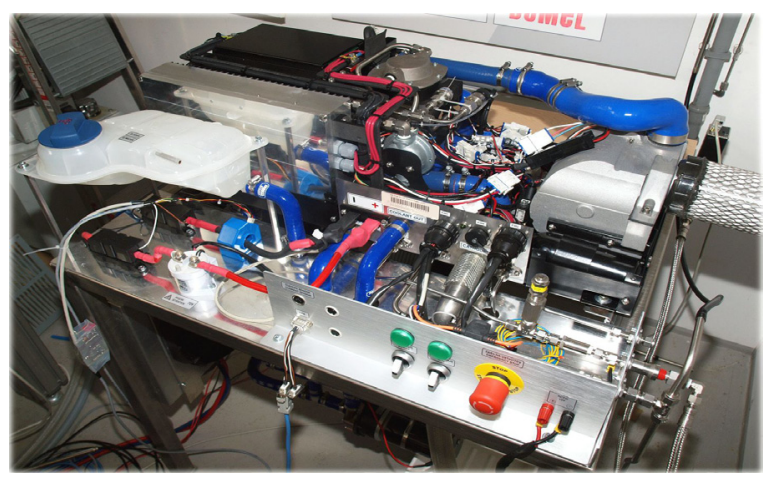

Fig. 2. PEM fuel cell system

An AMREL PLW9K-120-1000E electronic load (e-load) was used to simulate an ohmic load on the one hand, and to excite the power unit in the proper way on the other. The e-load can be externally controlled by a function generator. This allows setting a desired waveform of the e-load current that is drawn from the power unit. For this purpose a Tektronix AFG 3101 function generator was used. In other words, this subsystem allows the desired waveform of a current to be applied to the fuel cell system by setting the function generator parameters (frequency, offset, amplitude).

The final subgroup of the measurement setup consists of the sensors and the DAQ equipment. The components of this subgroup are further divided in two groups based on the fact if the component is to be used in a future diagnostic system, or it is not to be needed. The choice of the components in the first group was subjected to the desire of constructing a diagnostics system for commercial applications in the long run, based on the knowledge presented in this paper. Above all, components of such a system must be cost acceptable. Thus, in the first group are voltage and current sensors, which in future work will remain as they are. The voltage signals were measured using an in-house-developed voltage sensor comprising a galvanic isolator and an input bandpass filter with lower and upper cut-off frequencies at $3.7 \mathrm{~Hz}$ and $3.4 \mathrm{kHz}$, respectively. Due to its considerable influence, the frequency response of the voltage sensor is required (and it was recorded) for further compensation of the impedance results. The current signals were measured using a low-cost LEM LA 100-P Hall-Effect-based current transducer with a much higher upper cut-off frequency (i.e., $200 \mathrm{kHz}$ ) and, consequently, a negligible influence on a frequency response of current measurements. In the second group are sensors and DAQ equipment that will either not be needed or will be replaced with inhouse developed electronics in the future diagnostic system. These components are air temperature and air humidity sensors, a National Instruments USB6215 DAQ-board, and a PC with in-house designed LabView-based EIS measurement software.

During the experiments four quantities (i.e. voltage, current, temperature and relative humidity) were measured with four different sensors. In Table 1, standard uncertainties and measuring ranges of all the sensors are presented.

Table 2. Standard uncertainties and measuring range of the used sensors

\begin{tabular}{lll}
\hline Sensor & Standard Uncertainty & Range \\
\hline Voltage & $1.55 \mathrm{mV}$ & $\pm 10 \mathrm{~V}$ \\
\hline Current & $0.11 \mathrm{~A}$ & $\pm 150 \mathrm{~A}$ \\
\hline Temperature & $0.06^{\circ} \mathrm{C}$ & -40 to $180^{\circ} \mathrm{C}$ \\
\hline Relative Humidity & $1.73 \% \mathrm{RH}$ & 0 to $100 \% \mathrm{RH}$ \\
\hline
\end{tabular}


Measurement of air temperature and relative humidity were performed only to give a rough estimation of environmental parameters. The uncertainty of these two measurements does not affect the measurement of impedance, which is the main objective of this study. Since the air temperature and relative humidity were not under control (as this is a real-life situation), their estimated extended uncertainties are $1.5{ }^{\circ} \mathrm{C}$ and $5 \% \mathrm{RH}$, respectively. Because of frequency analyses, the voltage and current sensors measurement uncertainties negligibly affect final impedance result. The uncertainty of the impedance is therefore mainly affected by the changes in stack itself, which is taken into account in the decision algorithm.

\subsection{Measurement Parameters}

Measurement parameters that have to be set in the right way are the operating point, $\mathrm{AC}$ amplitude, excitation frequencies, and sampling frequencies. All the measurements were performed at the same operating point at $40 \mathrm{~A} \mathrm{DC}\left(I_{d c}\right)$, since this is a working point where the fuel cell system operates in the area of its highest efficiency. The amplitude of the sinusoidal current perturbation signal was set to $1 \mathrm{~A}\left(I_{0}\right)$. In this way, it represents approximately $2 \%$ of the DC current and is therefore small enough not to cause problems due to the non-linear nature of the real system. Due to the limitations set by our voltage sensor, the measurements were performed in the frequency range from $1 \mathrm{~Hz}$ to $1 \mathrm{kHz}$. The following frequencies of the perturbation signal were used: 1,2 , $5,10,12,15,20,30,40,50,100,200,300,500$, and $1000 \mathrm{~Hz}$. The frequencies were chosen in such a way that the resulting points in the Nyquist diagram are evenly distributed and clearly describe the system's impedance characteristic. At excitation frequencies up to $50 \mathrm{~Hz}$ the sampling frequency was $600 \mathrm{~Hz}$, while at higher excitation frequencies it was set to $6 \mathrm{kHz}$.

\subsection{Experiments}

Three sets of measurements were conducted at different environment conditions, i.e. sets in normal, dry, and moist environments. To perform appropriate experiments, imitations of dry and humid environments were prepared in order to provoke fuel cell system drying and flooding.

The measurements under normal operating conditions were conducted in a normal (non-modified) environment. At an air temperature of $25 \pm 1.5^{\circ} \mathrm{C}$ and a relative humidity of $30 \pm 5 \% \mathrm{RH}$, the values are within the specified operating environment parameters provided by the manufacturer.

In order to stimulate drying and flooding inside the fuel cells two different setups for providing inlet air were constructed. A dry environment was simulated by feeding the system with air from the pneumatic compressor, where air is dehumidified after compressed. An air pipe with a diameter wider than the inlet air filter diameter was used to lead the air to the inlet filter. In this way, dry air was blown over the inlet air filter and entered in the system, while the environmental air was blocked. The air parameters were a temperature of $25 \pm 1.5{ }^{\circ} \mathrm{C}$ and a relative humidity of $4 \pm 5 \% \mathrm{RH}$. The moist environment was simulated by using hot water. The moist air was captured right above the water level, where its relative humidity was very high and was led to the inlet air filter via the air pipe. The air parameters were a temperature of $55 \pm 1.5^{\circ} \mathrm{C}$ and a relative humidity of $98 \pm 5 \%$ RH.

\section{RESULTS}

\subsection{Computation of the Impedance}

The real fuel cell system operation is subjected to influences from the electrical subsystems and the environment, so the measurements are corrupted by a measurement noise. Furthermore, the real system is not linear, as assumed in the theoretical EIS background given in Section 1. Therefore, the acquired signals in reality do not have a pure sinusoidal waveform. Consequently, the impedance computation cannot be made by the straightforward application of Eqs. (1) through (5). Instead, the appropriate signal-processing techniques must be employed.

The calculations of the impedance were carried out in the following procedure for each measurement at each excitation frequency:

- applying the Hamming window to both the current and voltage datasets [25],

- calculating the fast Fourier transform (FFT) of both datasets [25],

- extracting the FFT values at the excitation frequency,

- calculating the impedance by dividing the extracted FFT voltage by FFT current values,

- compensating the result for the voltage sensor's influence in order to obtain the final impedance. 


\subsection{Impedance Characteristics}

As pointed out in Section 2.3 three different sets of measurements were conducted. With the use of the impedance computation, these sets yielded three impedance characteristics of the fuel cell system in case of normal operating conditions, and in presence of flooding and drying. The characteristics are presented in the form of Nyquist plots in Fig. 3 (normal operating conditions - black dashed line, drying - red dotted line, and flooding - blue dash-dot line). The points of these lines are calculated as the average of 15 consecutive measurements of the impedance (the three lines are only presented to better visualize the characteristics). Those impedance measurements are in Fig. 3 presented as crosses - normal, dots - drying, and circles - flooding.

The results in Fig. 3 affirm the possibility to perform EIS diagnostics of a larger PEM fuel cell system. The impedance characteristics of the system in case of different operating conditions clearly differentiate from each other, which makes the diagnostics possible. However, it is clear that the results in low frequency region below $20 \mathrm{~Hz}$ overlap and therefore the diagnostics cannot be performed in this frequency region. This observation can be addressed to low-frequency disturbances (e.g., jumping of the voltage because of water collecting on the cathode and the voltage gain during a hydrogen purge), and not strictly stationary nature of the system.
With regard to the results, the appropriate frequency range for diagnostics is from 20 to $300 \mathrm{~Hz}$. The results indicate that at lower frequencies up to $50 \mathrm{~Hz}$ only the real part of the impedance can be used for diagnostics because the imaginary part does not change much. In contrary, at higher frequencies above $100 \mathrm{~Hz}$ both parts can be used for diagnostics, as they both change substantially.

At frequencies up to $50 \mathrm{~Hz}$ a decrease in the real part value indicates flooding, while an increase indicates drying. At higher frequencies above $100 \mathrm{~Hz}$ a decrease in the real part value together with an increase in the imaginary part value implies flooding, whereas vice versa situation occurs in the case of drying.

\subsection{Decision Algorithm}

The results present a solid base for constructing a decision algorithm for diagnostics. The main goal of such algorithm is to classify input data (the impedance measurements) in to three classes - namely normal, flooding, and drying. As pointed out in section 3.2, diagnostics for case-study fuel cell system is possible in frequency area between 20 and $300 \mathrm{~Hz}$. So, the first step in constructing the algorithm is the selection of appropriate frequencies at which measurements will be performed. From the algorithm complexity and data acquisition duration point of view, a lower number of chosen frequencies is preferred. On the other hand,

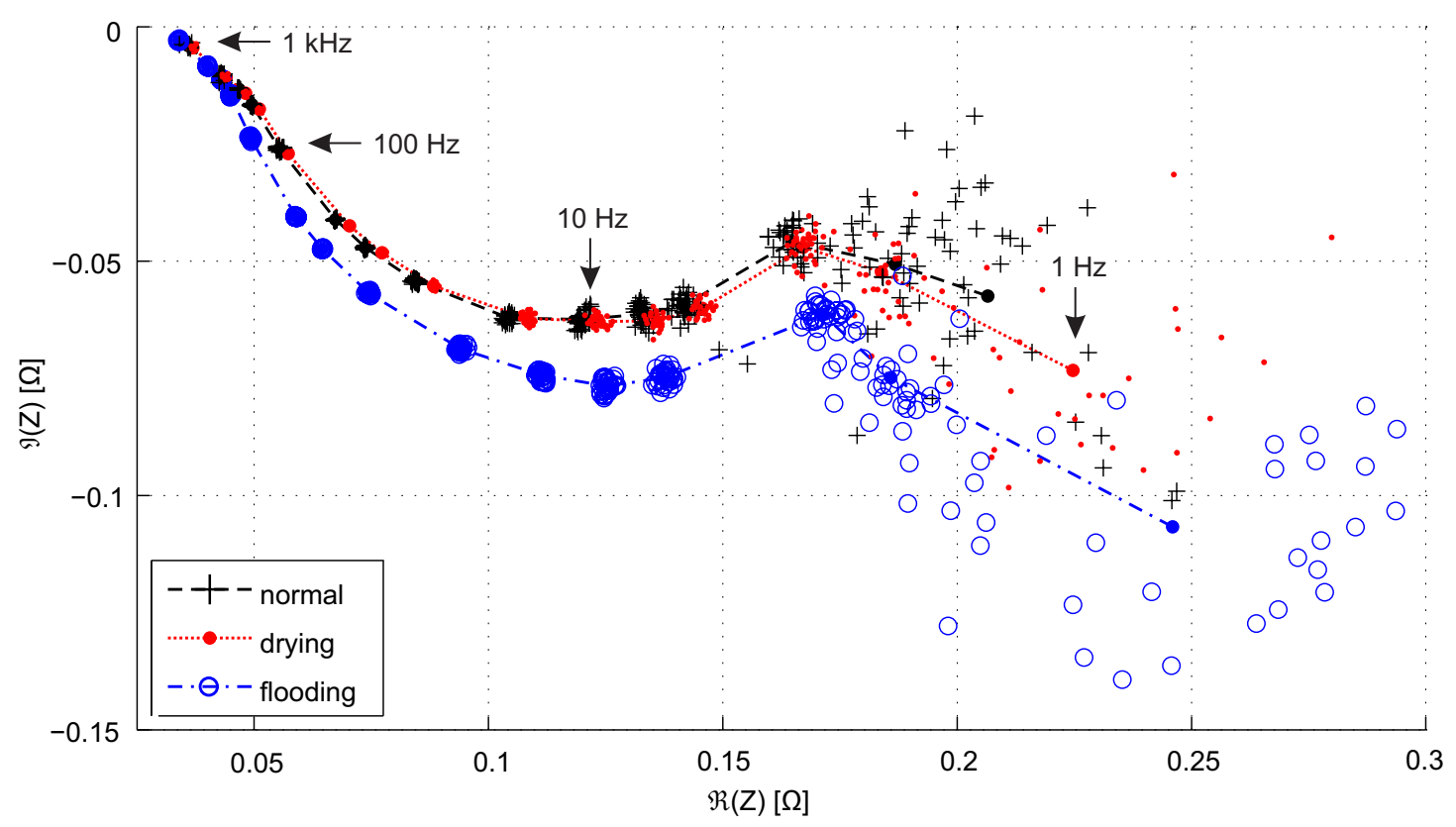

Fig. 3. Nyquist plots of the system impedance at normal operation, in presence of flooding, and in presence of drying 
when reliability and robustness is under consideration, more input information normally results in a more reliable and robust algorithm. Considerring both sides, three frequencies were selected, i.e. 30, 100, and $300 \mathrm{~Hz}$. These frequencies were chosen because they cover the entire interesting frequency range and because they are evenly spread across the frequency domain in terms of logarithmic scale.The three chosen impedances consist of six numerical values, but because the real part of the impedance at $30 \mathrm{~Hz}$ does not provide any additional information, only the remaining five are selected as algorithm's input numerical features. Therefore, in total there are three real part values and two imaginary ones.

For the decision algorithm, borders that separate the three classes must be constructed. For this purpose the following procedure is proposed, where the borders are derived from the performed measurement based on their mean and standard deviation values. In general, at each frequency two borders (i.e. normalflooding and normal-drying) have to be computed separately for the real and imaginary parts. Therefore, four border values are computed in total for each frequency. However, only two border values are computed in the case of $30 \mathrm{~Hz}$, since only real part of the impedance is considered relevant.

The borders at each frequency are computed based on the measurement data in such a way that the following equality equations hold true:

$$
\begin{aligned}
& \overline{\mathfrak{R}\left\{Z_{n o}\right\}}-k_{1} \sigma_{\Re, n o}=\overline{\Re\left\{Z_{f l}\right\}}+k_{1} \sigma_{\Re, f l}, \\
& \overline{\mathfrak{R}\left\{Z_{n o}\right\}}+k_{2} \sigma_{\Re, n o}=\overline{\mathfrak{R}\left\{Z_{d r}\right\}}-k_{2} \sigma_{\mathfrak{R}, d r}, \\
& \overline{\mathfrak{I}\left\{Z_{n o}\right\}}+k_{3} \sigma_{\Im, n o}=\overline{\mathfrak{I}\left\{Z_{f l}\right\}}-k_{3} \sigma_{\Im, f l}, \\
& \overline{\mathfrak{T}\left\{Z_{n o}\right\}}-k_{4} \sigma_{\Im, n o}=\overline{\mathfrak{I}\left\{Z_{d r}\right\}}+k_{4} \sigma_{\mathfrak{I}, d r} .
\end{aligned}
$$

In Eqs. (6) through (9), $\overline{\mathfrak{R}\left\{Z_{n o}\right\}}, \overline{\Re\left\{Z_{f l}\right\}}$ and $\overline{\mathfrak{R}\left\{Z_{d r}\right\}}$ represent the mean value of the impedance real parts. Similarly, $\overline{\mathfrak{I}\left\{Z_{n o}\right\}}, \overline{\mathfrak{I}\left\{Z_{f l}\right\}}$ and $\overline{\mathfrak{I}\left\{Z_{d r}\right\}}$ are the mean value of the imaginary parts. $\sigma_{\Re, n o}, \sigma_{\mathfrak{R}, f l}$ and $\sigma_{\Re, d r}$ are standard deviations of the real parts, $\sigma_{\Im, n o}, \sigma_{\widetilde{J}, f l}$ and $\sigma_{\widetilde{\Im}, d r}$ are standard deviations of the imaginary parts, and $k_{1}, \ldots, k_{4}$ are search variables.

From Eqs. (6) through (9) all four border equations are derived:

$$
Z_{\Re, n o-f l}=\overline{\Re\left\{Z_{n o}\right\}}-\frac{\left|\overline{\Re\left\{Z_{n o}\right\}}-\overline{\Re\left\{Z_{f l}\right\}}\right|}{\sigma_{\Re, n o}+\sigma_{\Re, f l}} \sigma_{\Re, n o},
$$

$$
\begin{aligned}
& Z_{\Re, n o-d r}=\overline{\mathfrak{R}\left\{Z_{n o}\right\}}+\frac{\left|\overline{\mathfrak{R}\left\{Z_{n o}\right\}}-\overline{\Re\left\{Z_{d r}\right\}}\right|}{\sigma_{\Re, n o}+\sigma_{\Re, d r}} \sigma_{\Re, n o}, \\
& Z_{\Im, n o-f l}=\overline{\mathfrak{I}\left\{Z_{n o}\right\}}+\frac{\left|\overline{\mathfrak{I}\left\{Z_{n o}\right\}}-\overline{\mathfrak{I}\left\{Z_{f l}\right\}}\right|}{\sigma_{\mathfrak{\Im}, n o}+\sigma_{\mathfrak{J}, f l}} \sigma_{\mathfrak{I}, n o}, \\
& Z_{\mathfrak{\Im}, n o-d r}=\overline{\mathfrak{I}\left\{Z_{n o}\right\}}-\frac{\left|\overline{\mathfrak{I}\left\{Z_{n o}\right\}}-\overline{\mathfrak{I}\left\{Z_{d r}\right\}}\right|}{\sigma_{\mathfrak{I}, n o}+\sigma_{\mathfrak{I}, d r}} \sigma_{\mathfrak{I}, n o} .
\end{aligned}
$$

Table 3 and Fig. 4 illustrate the proposed computation procedure, where the Table 3 outlines the numerical values of the computed borders and Fig. 4 graphically presents them. In addition, $2 \sigma$ areas $(95 \%$ confidence) of the measurements from which the borders were derived are presented in the figure.

Once the borders are computed, the decision algorithm is straight forward. The algorithm simply compares the input numerical features with the belonging border values and decides to which class the input feature belongs to. In other words, the algorithm tags each input feature with normal, flooding or drying tag. Since there are five input features and they can be in general tagged with different tags, the algorithm has to merge the intermediate result into

\begin{tabular}{|c|c|c|c|}
\hline \multirow{2}{*}{$f[\mathrm{~Hz}]$} & \multirow{2}{*}{ Part } & \multicolumn{2}{|c|}{ Border Value [m $\Omega$ ] } \\
\hline & & normal-flooding & normal-drying \\
\hline 30 & $\mathfrak{R}$ & 78.24 & 86.43 \\
\hline \multirow{2}{*}{100} & $\mathfrak{R}$ & 51.15 & 56.61 \\
\hline & $\mathfrak{I}$ & -24.78 & -26.78 \\
\hline \multirow{2}{*}{300} & $\mathfrak{R}$ & 44.72 & 47.38 \\
\hline & $\mathfrak{J}$ & -12.06 & -13.79 \\
\hline
\end{tabular}
one final. Therefore, the algorithm defines the final result by choosing the one tag, which is tagged to the majority of the features (e.g. three features are tagged with normal and the other two with drying, the final result is normal).

Table 3. Border values computed based on the presented measurements

\section{DISCUSSION}

The diagnostics of a commercial fuel cell system consisting of a few dozen cells, where only the impedance of the entire stack is measured, is a challenging task. Since not all the cells inside the 


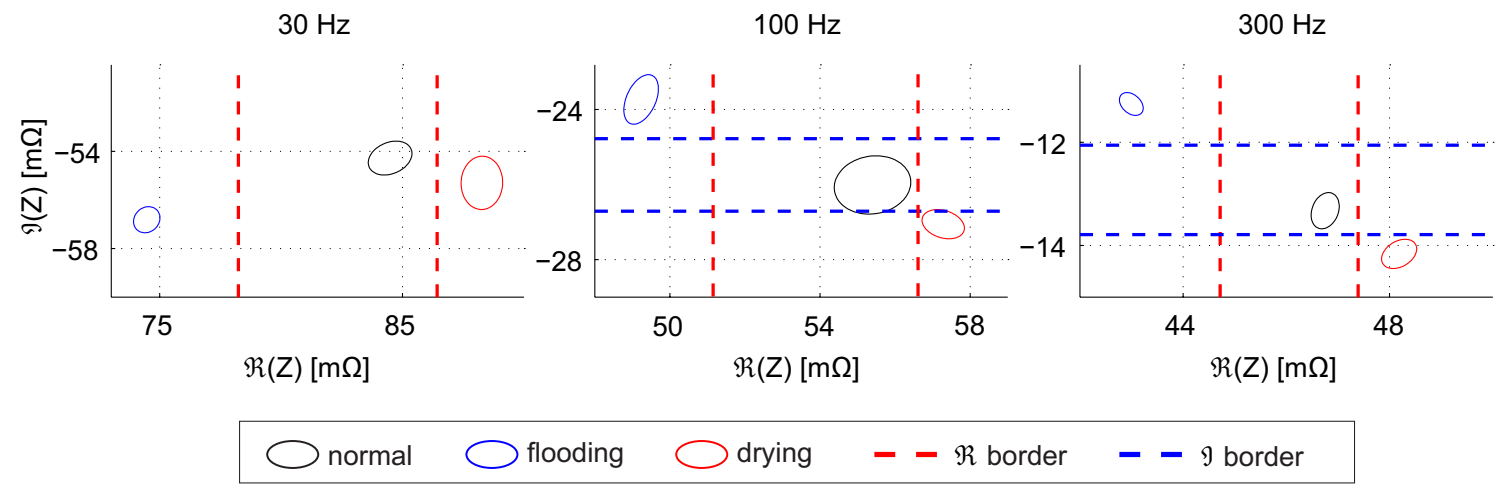

Fig. 4. Graphically presented borders

stack get flooded or dried, the total impedance of the system is not affected as much as in case of a shortstack system, and thus the change is hard to detect. In contrast to short-stack measurements there is yet another important difference, which is non-negligible influences of the system's electrical subsystems. In other words, these influences can be neglected in case of short-stack measurements, but with commercial systems, these influences significantly affect the measurement data, so steps to exclude them have to be taken.

The successfully performed measurements and results prove a few important things. Firstly, the used low-cost voltage and current sensors are appropriate for such measurements. Consequently, in future work these sensors will be used for building up a new diagnostic system. Secondly, the signal processing, impedance computation, and sensor compensation are done in the right way. Finally, the diagnostics can be carried out successfully, since the impedance characteristic of the system in the presence of different faults differentiate from each other. The conclusion is that the EIS measurements and diagnostics can also be performed on a larger commercially available system without using special EIS measurement equipment. The main advantage of the proposed border computation and decision algorithm is simplicity, which is an important feature when the algorithm has to work with limited computation resources (i.e. embedded systems) and in real time. However, to increase the robustness of the algorithm some additional decision rules can be added, especially when the real and imaginary value of the impedance at the same frequency are labelled with different tags.

\section{CONCLUSION}

The work presented shows that the EIS based diagnostics of flooding and drying inside a larger commercially available PEM fuel cell system is possible. It also proves the suitability of the chosen voltage and current sensors, and the effectiveness of the entire proposed computation of the impedance. The next stage of work will deal with the implementation of the EIS into complete diagnostic system, which will be appropriate for implementation into commercial systems as on-board diagnostic system.

\section{ACKNOWLEDGEMENT}

The authors thank the Centre of Excellence for Low-carbon Technologies - CO NOT, financed by the Slovenian Ministry of Higher Education, Science and Technology and co-financed by the European Regional Development Fund, Slovenian Research Agency (P2-0001) and the project EXLIZ - CZ.1.07/2.3.00/30.0013, which is co-financed by the European Social Fund and the state budget of the Czech Republic for their financial support.

\section{NOMENCLATURE}

Symbols
$i[\mathrm{~A}]$
$I[\mathrm{~A}]$
$I_{0}[\mathrm{~A}]$
$I_{\mathrm{dc}}[\mathrm{A}]$
$j$
$k_{1}, \ldots, k_{4}$
$t[\mathrm{~s}]$
$u[\mathrm{~V}]$
$U[\mathrm{~V}]$
$U_{0}[\mathrm{~V}]$

current
current phasor
current amplitude
current DC component
imaginary unit
search variables
time
voltage
voltage phasor
voltage amplitude




$\begin{array}{ll}U_{\mathrm{dc}}[\mathrm{V}] & \text { voltage DC component } \\ Z[\Omega] & \text { impedance } \\ Z_{0}[\Omega] & \text { impedance amplitude } \\ \mathfrak{R}(Z)[\Omega] & \text { real part of impedance } \\ \mathfrak{I}(Z)[\Omega] & \text { imaginary part of impedance } \\ \sigma[\Omega] & \text { standard deviation } \\ \Phi[\mathrm{rad}] & \text { impedance phase shift } \\ \varphi[\mathrm{rad}] & \text { phase shift } \\ \omega_{0}[\mathrm{rad} / \mathrm{s}] & \text { angular frequency }\end{array}$

Subscripts

no normal

fl flooding

dr drying

no-fl border between normal and flooding

no-dr border between normal and drying

\section{REFERENCES}

[1] Barbir, F. (2005). PEM Fuel Cells: Theory and Practice. Elsevier, Amsterdam.

[2] Srinivasan, S. (2006). Fuel Cells - From Fundamentals to Applications. Springer Science-Business Media LLC, New York.

[3] McGuiness, P. (2008). Fuelling the Car of the Future. Strojniški vestnik - Journal of Mechanical Engineering, vol. 54, no. 5, p. 356-363.

[4] Lotrič, A., Sekavčnik, M., Kunze, C., Spliethoff, H. (2011). Simulation of water-gas shift membrane reactor for integrated gasification combined cycle plant with $\mathrm{CO}_{2}$ capture. Strojniški vestnik - Journal of Mechanical Engineering, vol. 57, no. 12, p. 911-926, DOI:10.5545/ sv-jme.2011.100.

[5] Pirc, A., Sekavčnik, M., Mori, M. (2012). Universal model of a biomass gasifier for different syngas compositions. Strojniški vestnik - Journal of Mechanical Engineering, vol. 58, no. 5, p. 294-299, DOI:10.5545/sv-jme.2011.101.

[6] Jovan, V., Perne, M., Petrovčič, J. (2010). An assessment of the energetic flows in a commercial PEM fuel-cell system. Energy Conversion and Management, vol. 51, no. 12, p. 2467-2472, DOI:10.1016/j. enconman.2010.04.014.

[7] Wu, J., Yuan, X.Z., Martin, J.J., Wang, H., Zhang, J., Shen, J., Wu, S., Merida, W. (2008). A review of PEM fuel cell durability: Degradation mechanisms and mitigation strategies. Journal of Power Sources, vol. 184, no. 1, p. 104-119, DOI:10.1016/j. jpowsour.2008.06.006.

[8] Gerbec, M., Jovan, V., Petrovčič, J. (2008). Operational and safety analyses of a commercial PEMFC system. International Journal of Hydrogen Energy, vol. 33, no. 15, p. 4147-4160, DOI:10.1016/j.ijhydene.2008.04.063.

[9] Schmittinger, W., Vahidi, A. (2008). A review of the main parameters influencing long-term performance and durability of PEM fuel cells. Journal of Power
Sources, vol. 180, no. 1, p. 1-14, DOI:10.1016/j. jpowsour.2008.01.070.

[10] Pregelj, B., Vrečko, D., Jovan, V. (2011). Improving the operation of a fuel-cell power unit with supervision control - A simulation study. Journal of Power Sources, vol. 196, no. 22, p. 9419-9428, DOI:10.1016/j. jpowsour.2011.06.077.

[11] Borup, R.L., Davey, J.R., Garzon, F.H., Wood, D.L., Inbody, M.A. (2006). PEM fuel cell electrocatalyst durability measurements. Journal of Power Sources, vol. 163, no. 1 (Spec. iss.), p. 76-81, DOI:10.1016/j. jpowsour.2006.03.009.

[12] Borup, R., Meyers, J., Pivovar, B., Kim, Y.S., Mukundan, R., Garland, N., Myers, D., Wilson, M., Garzon, F., Wood, D., Zelenay, P., More, K., Stroh, K., Zawodzinski, T., Boncella, J., McGrath, J.E., Inaba, M., Miyatake, K., Hori, M., Ota, K., Ogumi, Z., Miyata, S., Nishikata, A., Siroma, Z., Uchimoto, Y., Yasuda, K., Kimijima, K.-I., Iwashita, N. (2007). Scientific aspects of polymer electrolyte fuel cell durability and degradation. Chemical Reviews, vol. 107, no. 10, p. 3904-3951, DOI:10.1021/cr0501821.

[13] Farrell, C., Gardner, C., Ternan, M. (2007). Experimental and modelling studies of $\mathrm{CO}$ poisoning in PEM fuel cells. Journal of Power Sources, vol. 171, no. 2, p. 282-293, DOI:10.1016/j.jpowsour.2007.07.006.

[14] Cheng, X., Shi, Z., Glass, N., Zhang, L., Zhang, J., Song, D., Liu, Z.-S., Wang, H., Shen, J. (2007). A review of PEM hydrogen fuel cell contamination: Impacts, mechanisms, and mitigation. Journal of Power Sources, vol. 165, no. 2, p. 739-756, DOI:10.1016/j. jpowsour.2006.12.012.

[15] Song, Y., Xu, H., Wei, Y., Kunz, H.R., Bonville, L.J., Fenton, J.M. (2006). Dependence of high-temperature PEM fuel cell performance on Nafion content. Journal of Power Sources. vol. 154, no. 1, p. 138-144, DOI:10.1016/j.jpowsour.2005.04.001.

[16] Yan, Q., Toghiani, H., Lee, Y.-W., Liang, K., Causey, H. (2006). Effect of sub-freezing temperatures on a PEM fuel cell performance, startup and fuel cell components. Journal of Power Sources, vol. 160, no. 2, p. 12421250, DOI:10.1016/j.jpowsour.2006.02.075.

[17] Li, H., Tang, Y., Wang, Z., Shi, Z., Wu, S., Song, D., Zhang, J., Fatih, K., Zhang, J., Wang, H., Liu, Z., Abouatallah, R., Mazza, A. (2008). A review of water flooding issues in the proton exchange membrane fuel cell. Journal of Power Sources, vol. 178, no. 1, p. 103 117, DOI:10.1016/j.jpowsour.2007.12.068.

[18] Yuan, X.Z., Song, C., Wang, H., Zhang, J. (2010). Electrochemical Impedance Spectroscopy in PEM Fuel Cells, Fundamentals and Applications, Springer, London, DOI:10.1007/978-1-84882-846-9.

[19] Yuan, X., Wang, H., Sun, J.C., Zhang, J. (2007). AC impedance technique in PEM fuel cell diagnosis - A review. International Journal of Hydrogen Energy, vol. 32, no. 17, p. 4365-4380, DOI:10.1016/j. ijhydene.2007.05.036. 
[20] Miller, M., Bazylak, A. (2011). A review of polymer electrolyte membrane fuel cell stack testing. Journal of Power Sources, vol. 196, no. 2, p. 601-613, DOI:10.1016/j.jpowsour.2010.07.072.

[21] Fouquet, N., Doulet, C., Nouillant, C., Dauphin-Tanguy, G., Ould-Bouamama, B. (2006). Model based PEM fuel cell state-of-health monitoring via ac impedance measurements. Journal of Power Sources, vol. 159, no. 2, p. 905-913, DOI:10.1016/j.jpowsour.2005.11.035.

[22] Le Canut, J.-M., Abouatallah, R.M., Harrington, D.A. (2006). Detection of Membrane Drying, Fuel Cell Flooding, and Anode Catalyst Poisoning on PEMFC Stacks by Electrochemical Impedance Spectroscopy.
Journal of The Electrochemical Society, vol. 153, no. 5, p. A857-A864, DOI:10.1149/1.2179200.

[23] Brunetto, C., Moschetto, A., Tina, G. (2009). PEM fuel cell testing by electrochemical impedance spectroscopy. Electric Power Systems Research, vol. 79, no. 1, p. 1726, DOI:10.1016/j.epsr.2008.05.012.

[24] Wasterlain, S., Candusso, D., Harel, F., Hissel, D., François, X. (2011). Development of new test instruments and protocols for the diagnostic of fuel cell stacks. Journal of Power Sources. vol. 196, no. 12, pp. 5325-5333, DOI:10.1016/j.jpowsour.2010.08.029.

[25] Oppenheim, A., Schafer, R. (1998). Discrete-Time Signal Processing, Prentice Hall, New Jersey. 